\title{
FROEBELIAN LITERATURE IN KINDERGARTEN TRAINING
}

\author{
NINA C. VANDEWALKER \\ Milwaukee State Normal School
}

The kindergarten has been a slow growth. Its underlying theory was the result of many influences; its technique the product of years of thought. Because it was conceived before an adequate study of the child's development had been made, however, the reorganization both of its theory and practice was inevitable. Had the larger knowledge of later years been brought to bear upon the kindergarten before its procedure had assumed fixed forms, however, less reorganization would have been necessary. The inadequate knowledge upon which the kindergarten was originally based is one reason for the reconstruction that is now in progress; the fact that its procedure developed apart from the movement which has given general education its present basis is another. Some of the defects in kindergarten procedure today grow out of methods adopted by kindergarten training schools during the early years. Since these methods have not yet been fully outgrown the reconstruction of the kindergarten involves a reconstruction in kindergarten training as well.

The incorporation of the kindergarten into the school system was the goal of kindergarten effort even in the early years of the movement; that such incorporation would involve a co-ordination of kindergarten theory and practice with the theory and practice of the school was but vaguely realized, if realized at all. The kindergarten leaders therefore took little note of general education until they were compelled to do so at a later period by the incorporation of the kindergarten into the school. The procedure of the kindergarten was therefore built up without reference to educational procedure beyond the kindergarten, and methods of training were evolved in which those employed in the training of other teachers received little recognition. The difficulties in 
the kindergarten situation today are in no small degree the result of these facts.

The fact that the organization and methods of the training school tended in some respects in the direction of weakness rather than of strength did not become apparent until the adoption of the kindergarten by the school became general. When kindergartners and grade teachers came to work side by side, it became evident that the kindergartner outranked the grade teacher on some points but that she fell below in others. Her strength was found to lie in her sympathetic attitude toward children, her enthusiasm for the kindergarten and the doctrines it represents, and her fine womanliness; her weakness in the early days, lay in her lack of adequate scholarship, her blind following of precedent in method, and her ignorance of, and indifference to, general education. An inquiry into the causes of these weaknesses showed them to be in large measure the result of the methods adopted in kindergarten training schools.

A teacher may adopt one of two attitudes in the work of instruction - the dogmatic or the inquiring. If the first is adopted he will present knowledge to his students for their acceptance; if the second, he will seek to have them acquire it for themselves. The first attitude in the teacher makes the student depend upon authority; the second leads him to do independent thinking. The tendency to follow authority only, on the part of any group of people, indicates that the teaching has been dogmatic in character; the ability on the part of another to do independent thinking indicates that the teaching received has been characterized by the spirit of inquiry. The fact that kindergartners are so generally followers instead of thinkers is circumstantial evidence that in the past at least, dogmatic methods have been the rule in kindergarten training schools. To call attention to this aspect of the methods adopted by kindergarten training teachers is the purpose of this paper.

The kindergarten training course doubtless raised many questions while in process of evolution-questions of subject-matter as well as of method. Its organization as compared with the organization of a normal-school course is of interest, but those 
who wish information upon it are referred to the article entitled "The Curriculum and Methods of the Kindergarten Training School," in the Kindergarten Review, Vol. XIII, p. 642. This paper must confine itself to one phase of training school workthe methods of teaching the kindergarten subjects. Since the study of these subjects calls for the reading of Froebel's most important contributions to educational literature, the discussion of the first will imply a discussion of the second likewise.

The making of a kindergartner calls for instruction in several different lines, but the most important phrase of kindergarten training is the kindergarten instruction proper. As customarily given this instruction falls into several lines. Upon entering the course in the average training school, the student is assigned to practice-teaching during the morning, and is scheduled for several lines of work in the afternoon, reciting in each subject once or twice a week. Among these lines of work is a course in the kindergarten gifts, another in the occupations, still another in the mother plays, and usually one also in games. In each course frequent reference is made to the work of the other, but on the whole the several subjects are independent, and not phases of an organic whole. Since the students are wholly unfamiliar with all of these, and with the books used as textbooks-Froebel's Pedagogics of the Kindergarten and Education by Development in connection with the gifts and occupations, and the Mother-Play Book in connection with the mother plays, the instruction must of necessity be more or less dogmatic in character.

Such an organization of work doubtless seems right and justifiable to those responsible for it, and they would perhaps be surprised to learn that many educational experts regard it as violating the fundamental principles of educational procedure in several respects. The gifts, occupations, and games, are means to an end-the child's development. Unless that development receives the primary emphasis, and the means are studied with constant reference to that development, the student's conception of both end and means will be a wrong one. The fact that the kindergarten instrumentalities are studied first, or that the study of these is placed on the same level with the study of the child, 
gives an erroneous impression and places the emphasis where it does not belong. Such an organization of work would alone account for the undue exaltation of the kindergarten material which most kindergartners show.

The organization in question is further at fault in the fact that it begins, not with the student's fund of observation and experience, but with the unknown and the unfamiliar. When students begin with their own experiences and proceed by natural processes to the unknown they learn to think for themselves in the process; when they begin with something wholly new they can only accept. Kindergarten students know that the instrumentalities presented to them have value, though they may as yet be unable to see that value themselves. What can they do but take them on faith? When the methods employed in giving kindergarten instruction are considered, it is not surprising that independent thinking on the part of kindergartners should be the exception rather than the rule.

A course so organized is open to criticism on several other grounds. The kindergartner is said to lack interest in general education. How can she acquire such interest when Froebel alone is studied and the literature of general education is ignored and even avoided? She is said to lack scholarship. So large a part of her time is devoted to practice-teaching that the formation of scholarly habits is out of the question. When students are scheduled for half a dozen subjects, in each of which they recite but once or twice a week, thorough work is impossible. Because of the amount of practice-teaching required there is no time for the academic broadening that every student needs. That practiceteaching in the senior year would be of a much higher order if the junior year were devoted to the right kind of study does not yet seem to have occurred to kindergarten training teachers, although normal schools have long recognized that fact. The sins of the kindergartner may be many but the responsibility for a large proportion must be laid at the door of the training school.

Fortunately for the kindergarten cause, however, all kindergarten training is not organized upon the plan described. In a few institutions at least, a course has been adopted which is not 
open to the criticism in question. In this the correlating center of the whole is a study of the child's development, which continues throughout the junior year, and to which all the other phases of the work are related. The instruction in the kindergarten instrumentalities, which forms another course, is organized into one whole, the foundation of which is a study of the child's play and play material. This also continues throughout the year. The practice-teaching is postponed until the senior year because those in authority consider it unpedagogical to assign students to teaching before they have gained a knowledge of the aims of education, and of the means by which these aims are to be realized. The course includes several academic subjects that the students' scholarship may be strengthened.

A description of the different courses as such is not called for by this paper. As an aid to clearness of comprehension it may be said, however, that in the child-study course mentioned, important phases of the child's development are taken up, on the basis of observation, reading, and class discussion, and that the mother plays are studied in this setting. For a fuller discussion of such a course the reader is referred to an article by the writer, entitled "The Place of the Mother Play in the Training of Kindergartners," in the Kindergarten Review, Vol. XVIII, p. 6. The methods of beginning the course in the kindergarten instrumentalities is given in some detail since it illustrates points that will be more fully discussed.

The aim in this course is to lead students from the foundation which their own observation and experience furnishes to a gradual comprehension of the doctrines that underlie kindergarten procedure, and which are embodied in the Froebelian literature. The teacher begins therefore, by turning the student's attention to the games, play, and play material of their own childhood, leading them to consider the various forms of play, and the interests that underlie them. She will direct their attention also to the organized games, both as to form and content, and to the play material used at different ages. She may have them collect available nature material and use it for play purposes as children would, or as their own greater ingenuity directs. 
This reminiscent study should be accompanied by the observation of children's play wherever opportunity may offer. From this and their own recollections they may be led to the discovery of several of the principles that underlie kindergarten procedure.

From such a beginning the students can be led to the reading and discussion of the more important theories of play, the views of Froebel included. This in turn may be made the foundation for a more thorough study of the child's play from infancy upbefore the kindergarten period, during that period, and after it. The basis for such study must of necessity be the observation of children, and the reading of the literature of child-study bearing: upon the topic. With such a foundation the organized play of the kindergarten will assume a significance that it could not otherwise have. The work up to this point should be considered as the foundation for the study of the kindergarten instrumentalities as a whole. Should it seem desirable to study the games independently from this point on, it can be done without danger of separating them in the student's mind from their relation to the child's development.

The games as such form but one phase of the child's play, however. Of equal importance is the play that requires material. In the study of the child's play at different ages, already mentioned, many references will doubtless have been made to the child's use of material for play purposes. This phase of play should now be considered more fully, as before, on the basis of observation and reading. Children's play with balls and blocks in the nursery should be made the basis for the later study of the kindergarten gifts, and the nursery use of clay, sand, paper, pencils, and other materials the basis for a detailed study of the occupations. On such a foundation alone can the instruction in the gifts or occupations be considered pedagogical. When the students have grasped the necessary difference between play with material that retains its form, and that which is changed in the play process, the work may differentiate into a study of the gifts on the one hand, and of the occupations on the other. The methods of procedure with these, on the basis of the new views. 
have been so well indicated in the preceding papers of this series that a further discussion is unnecessary.

The two modes of organizing kindergarten instruction here presented, and the two kinds of method indicated show two different attitudes among kindergarten training teachers, the dogmatic and the inquiring. These attitudes, with the methods that result from them, produce kindergartners of very different types. The training teachers who embody the first attitude exalt Froebel and the kindergarten. Because of this the emphasis in their instruction is placed upon the study of the kindergarten instrumentalities instead of upon the study of the child. The literature that pertains to these instrumentalities- "Pedagogics of the Kindergarten," and "Education by Development"-is presented as authority to be accepted without question. The study of the child is made upon the basis of Froebel only, and the literature that deals with the child's development-the MotherPlay Book, is presented in the same spirit. To make the student see through Froebel's eyes instead of through her own is, consciously or unconsciously, the purpose of the work. It is the acceptance of Froebel's views that is sought for in the student, rather than the power of independent thinking.

The training teachers of the second type emphasize the study of the child instead of the study of the kindergarten instrumentalities. They regard these instrumentalities as the best series yet devised for the development of the child by means of his play activities but are unwilling to accept them as ultimate and final. Instead of presenting the gifts and occupations as a series to be accepted, therefore, the teachers of this type aim to give students such an insight into the principles that underlie children's play that they will be able to use the Froebelian materials or any others to further the child's development. In the study of the child they aim to present Froebel's views of its development, but not in such a manner as to compel their acceptance, until by a comparison with other views the student's own judgment has been satisfied. The attitude which they wish to cultivate toward Froebelian literature as toward any other, therefore, is the atti- 
tude of inquiry. It is needless to say that this attitude is in harmony with the spirit of modern education.

It may be asked whether the kindergarten would ever have attained its present status in American education if the inquiring instead of the positive attitude had been assumed at the beginning. It is doubtless true that the advocacy of a theory or an institution is needed for the inauguration of a movement, and there is little doubt that the dogmatic presentation of Froebel's views during the early years was a needed service to American education. Such presentation may continue too long, however, and thereby endanger the existence and progress of the movement it seeks to further. Any institution tends to assume fixed forms. If the underlying thought of that institution is sufficiently vital, these forms will give way at intervals because of growth from within. If the forms which represent it at a given period do not thus give way, the forms will remain but will lack life and substance. The forms which the kindergarten has assumed no longer represent current conceptions of that institution. The dogmatic presentation of Froebel's views at the present time is an attempt, therefore, to maintain a form which is no longer instinct with life. The acquainting of the American people with the views of Froebel was a great service but the present needs a different one.

The literature of American education has been materially enriched by the contributions of Froebel. Although many influences have combined to give that literature its present value, one of its most vital elements would have been lacking if at any time the contribution of Froebel had been eliminated. The influence of that contribution has deepened with the passing years, and there are at present few phases of educational effort in which it has not been felt. The presentation of Froebel's theories to American educators is largely the work of the kindergarten training teachers. In performing this important service, have they rendered the course of education the whole service which they should have rendered?

In acquainting the public with the literature of Froebel the training schools could hardly have labored more faithfully. It 
is estimated that more than twenty-five thousand young women have taken a kindergarten training course since the kindergarten has become a part of American life. All of these have therefore a first-hand acquaintance with Froebel's masterpieces. The mothers' clubs organized under training school auspices have added to the numbers of those who have studied Froebel more or less thoroughly. The additional number of those who have become familiar with Froebel's views as a result of the efforts of kindergarten graduates cannot be estimated. The majority of these have accepted Froebel's views with little question. It is because of their loyalty to, and their enthusiasm for, the Froebelian doctrines that the kindergarten movement has attained its present momentum.

Such a service challenges admiration, yet one cannot help asking what the effect would have been if Froebel had been taught less dogmatically. What would have been the effect upon the kindergarten and upon the application of Froebel's doctrines to general education if training teachers had emphasized the development of the child more and the technique by which that development is effected less; if the technique of the kindergarten had been studied as a phase of the problem of education by activity instead of something ultimate and final; and if the kindergarten games had been regarded as an initial attempt to show the significance and value of play for education and life, instead of a closed series to which no profane hand should dare to add and from which none should subtract? To know Froebel aright is to know the education of the present and to be able to forecast that of the future. In the Education of Man, written over eighty years ago, Froebel struck the keynote of current educational thought-that of education by development; in the Mother-Play Book, published seventeen years later he showed how the development a child has already attained can be made the basis for the more formal educational process; and in his Pedagogics he indicated a method by which the child's activities may be utilized for educational purposes. The lines of educational effort then inaugurated are now in the process of organization, not for the kindergarten alone but for general education. The 
kindergartner claims for Froebel the credit of inaugurating such lines of educational effort as child-study and education by activity, but she is unwilling to recognize value in any phases of such effort that are not carried out on strictly Froebelian lines. Many kindergartners are not only out of sympathy, therefore, with the great movements that are shaping American education, but have assumed an attitude of antagonism toward these and toward the literature that embodies them. Such an attitude must eventually bring disaster to the kindergarten, and retard the application of Froebel's doctrines to other lines of educational effort. The educational world at one time needed the presentation of Froebel's doctrines. A different service is needed at present-the reinterpretation of these doctrines from the standpoint of modern scholarship. It would have been appropriate for the kindergarten training teachers to lead in this service also, but in their desire to maintain the forms which the Froebelian doctrines have assumed, the majority have failed to perceive the new problems that have arisen. Because of this, the leadership in kindergarten thought is fast passing from the kindergarten training school to the university. The lines along which Froebelian influence will be exerted in general education have already been pointed out by university men, and such men are giving effective service in the reconstruction of kindergarten theory and practice. In the new educational era that has begun the doctrines of Froebel will receive greater emphasis than they have in the past. If these doctrines are to exert their fullest influence, however, there must be co-operation instead of antagonism between the forces that value such influence. The methods that have produced weakness in kindergarten instruction must be discarded and the attitudes and methods adopted that will make for strength and union with other educational forces. The literature of Froebel has proved a great stimulus to educational thought, but that stimulus is by no means exhausted. When it is approached in the spirit of modern thought its true value will become apparent. 